\title{
Actinomicose atípica em bovinos ${ }^{1}$
}

\begin{abstract}
Bianca Tessele ${ }^{2}$, Andréia Vielmo ${ }^{3}$, Márcia Hammerschmitt ${ }^{4}$ e Claudio S.L. Barros ${ }^{4 *}$
ABSTRACT.- Tessele B., Vielmo A., Hammerschmitt M. \& Barros C.S.L. 2014. [Atypical actinomycosis in cattle.] Actinomicose atípica em bovinos. Pesquisa Veterinária Brasileira 34(7):663-666. Departamento de Patologia, Universidade Federal de Santa Maria, Camobi, Santa Maria, RS 97105-900, Brazil. E-mail: claudioslbarros@uol.com.br

Cases of actinomycosis with atypical presentation are described in two oxen. In both cases there was a hard irregular and extensive lesions in the maxilla. The maxilla of both cattle became enlarged and honeycombed as a result of destructive rarefaction and regenerative bone proliferation. The cut surface of the lesions consisted of white glistening fibrous tissue within which numerous yellow caseous granules could be seen. Sinus tracts could be demonstrated within the lesions. In hematoxylin-eosin stained sections the lesions consisted of island of pyogranulomatous inflammation within an extensive fibrous stroma. In the center of the granuloma there was a basophilic irregular shaped mass surrounded by a zone radially arranged eosinophilic projections (Splendore-Hoeppli material). Around the radiating mass there was a zone of neutrophils, surrounded by a layer of epithelioid macrophages and occasional multinucleated giant cells. An outer layer of lymphocytes and plasma cells was present that limit the granuloma from the abundant fibrous tissue surrounding it. Up on Gram stain the central part of the colony revealed a tangled mass of rod shaped organisms morphologically consistent with Actinomyces bovis. Since the unusual presentation of this lesions misled the initial diagnosis the detailed description of these cases are reported here in the hopes it can help in the differential diagnosis by veterinary practitioners and met inspectors.
\end{abstract}

INDEX TERMS: Actinomycosis, Actinomyces bovis, osteomyelitis, atypical presentation, diseases of cattle.

RESUMO.- Casos de actinomicose com apresentação atípica são descritos em dois bovinos. Em ambos os casos notou-se uma aumento de volume extenso e duro na maxila. A maxila dos dois bovinos tomou um aspecto de favo de mel como resultado da rarefação destrutiva e da proliferação óssea regenerativa. Na superfície de corte as lesões consistiam de tecido fibroso branco e brilhante em meio ao qual numerosos grânulos amarelos podiam ser vistos. Tratos fistulosos podiam ser demonstrados em meio às lesões. Em cortes

\footnotetext{
${ }^{1}$ Recebido em 14 de junho de 2014.

Aceito para publicação em 16 de julho de 2014.

Parte da Tese de Doutorado do primeiro autor.

${ }^{2}$ Programa de Pós-Graduação em Medicina Veterinária, área de concentração em Patologia Veterinária, Centro de Ciências Rurais (CCR), Universidade Federal de Santa Maria (UFSM), Santa Maria, RS 97105-900, Brasil.

${ }^{3}$ Bolsista do PROBIC, FAPERGS (AV) e CNPq (MH) no Departamento de Patologia da UFSM, Santa Maria, RS.

${ }^{4}$ Departamento de Patologia, LPV, UFSM, Santa Maria, RS 97105-900. Pesquisador 1A do CNPq.*Autor para correspondência: claudioslbarros@ uol.com.br
}

corados pela hematoxilina e eosina as lesões consistiam de ilhas de inflamação piogranulomatosa em meio a extenso estroma fibroso. No centro do granuloma havia uma massa basofílica de forma irregular cercada por uma zona com projeções eosinofílicas radiadas (reação de Splendore-Hoeppli). Ao redor da massa radiada havia uma zona de neutrófilos cercada por uma camada de macrófagos epitelioides e ocasionais células gigantes multinucleadas. Uma camada externa de linfócitos e plasmócitos limitava o granuloma do extenso estroma conjuntivo que o cercava. $\mathrm{Na}$ coloração de Gram, a parte central da colônia revelava um aglomerado de micro-organismos em forma de bastonetes, com morfologia compatível com Actinomyces bovis. Uma vez que a apresentação pouco usual das lesões levou a má interpretação diagnóstica inicial nestes casos, a descrição detalhada das lesões é feita aqui com o objetivo de ajudar no diagnóstico diferencial feito por veterinários clínicos e inspetores de carne.

TERMOS DE INDEXAÇAO: Actinomicose, Actinomyces bovis, osteomielite, apresentação atípica, doença de bovinos. 


\section{INTRODUÇÃO}

Actinomicose é uma osteomielite piogranulomatosa, primariamente de bovinos causada pela bactéria gram-positiva Actinomyces bovis (Thompson 2007). Infecções ocasionais ocorrem em outras espécies, como porcos, veados, cães, ovinos, caprinos, cavalos (Smego \& Foglia 1998, Seifi et al. 2003, Thompson 2007, Vos 2007). Em seres humanos a lesão é causada por A. israeli (Jones et al. 1997). 0 osso afetado fica espessado em decorrência de múltiplos piogranulomas que dão à superfície de corte do osso a aparência de um favo de mel (Grist 2008).

Actinomicose bovina já foi erroneamente interpretada como osteossarcoma e posteriormente como uma lesão micótica (McFadyean 1932). Como essas últimas incluíam lesões na língua e linfonodos supõe-se que muitas se tratavam de actinobacilose. Esses "fungos" teriam como habitat o solo, grãos e palhas, sendo transmitidos para os bovinos através da ingestão desses vegetais (Boström 1890). Atualmente, sabe-se que essas matérias vegetais não são as carreadoras do agente, mas sim as responsáveis pela inoculação dele na cavidade oral de bovinos devido às abrasões que provocam na gengiva. A inoculação de A. bovis, um agente comensal da cavidade oral de animais, pode ocorrer também por pedaços afiados de corpos estranhos ou por erupções dentárias e periodontites, presumivelmente via linfáticos que drenam para o osso mandibular (Radostits 2007, Thompson 2007).

Embora actinomicose já tenha sido descrita em diferentes regiões anatômicas de bovinos, como pênis e traqueia (Basile \& Diniz 1979, Bertonce \& Rebhun 1984), a lesão clássica dessa doença em bovinos é localizada na mandíbula, raramente ocorrendo o envolvimento da maxila (Wilson 2005, Thompson 2007). 0 objetivo desse trabalho é descrever os aspectos macro e microscópicos de actinomicose no osso maxilar de dois bovinos abatidos em matadouro frigorífico. Como essas lesões foram incialmente interpretadas como carcinomas de células escamosas, é oportuno de orientar médicos veterinários e profissionais da inspeção para a apresentação e localização atípicas da doença.

\section{MATERIAL E MÉTODOS}

Foram recebidas nos Laboratório de Patologia Veterinária (LPV) da Universidade Federal de Santa Maria (UFSM) duas cabeças de bovinos abatidos em matadouro-frigorífico sob Inspeção Federal. Esses dois casos são parte de um total de dez casos de actinomicose em bovinos de matadouros-frigoríficos recebidos no LPV em um período de 42 meses. Os dois bovinos eram oriundos de propriedades localizadas em diferentes regiões do Rio Grande do Sul. Dados referentes à idade, raça ou sexo não foram informados. As cabeças foram fotografadas, serradas transversalmente; fragmentos representativos das lesões foram descalcificados e processados rotineiramente para histopatologia. Adicionalmente à coloração por hematoxilina eosina (HE), várias secções foram coradas pela técnica de Gram MacCallum-Goodpasture.

\section{RESULTADOS}

Ambas as cabeças estavam deformadas e aumentadas de volume por proliferação óssea do maxilar direito (Caso 1) e do maxilar esquerdo (Caso 2). No Caso 1 o aumento de volume da cabeça estendia-se lateral e cranialmente da re- gião infraorbitária direita até a região nasal. No Caso 2 a lesão iniciava próxima à base da orelha (Fig.1) e apresentava ventralmente ao olho esquerdo, na região do masseter, uma cavidade óssea preenchida por material necrótico enegrecido, friável e fétido (Fig.2).

Ao serrar as cabeças na porção média da cavidade nasal, observou-se proliferação óssea com múltiplos nódulos amarelos com aspecto caseoso, circundados por finos septos de tecido ósseo. No centro dessas áreas foram observados pequenos grânulos amarelos e duros (Fig.3). Outros nódulos estavam necróticos, evidenciados por áreas verdes escuras. Os tecidos moles sobrejacentes a essas áreas possuíam múltiplos trajetos fistulosos com material purulento, circundados por um tecido brancacento. Em ambos os casos as extensas áreas inflamatórias causavam destruição de parte dos cornetos nasais e obstrução quase que total da cavidade com desvio da cavidade nasal contralateral. Caudalmente, as lesões apresentavam maior proliferação de tecido ósseo e fibroso cicatricial com menos inflamação.

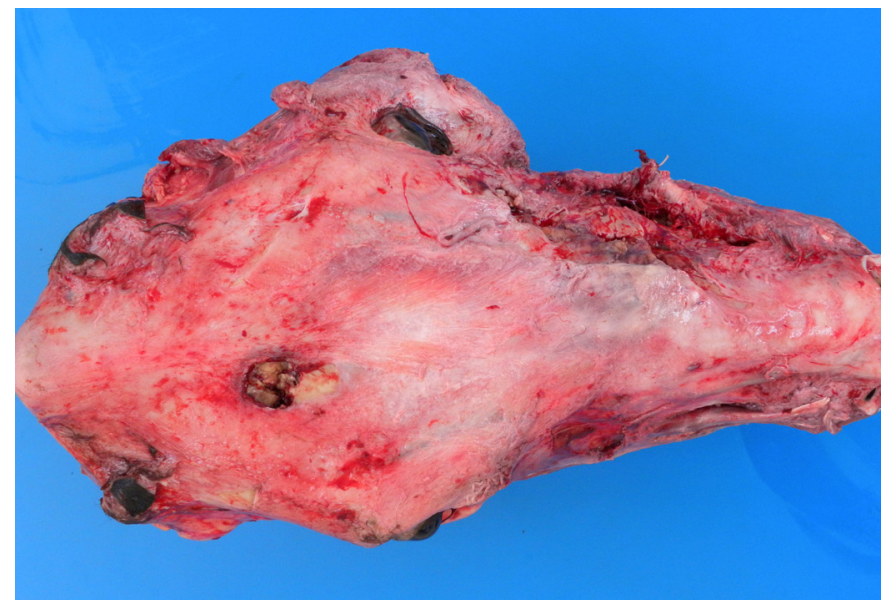

Fig.1. Actinomicose em bovino (Caso 2). No lado esquerdo há uma protuberância que inicia próxima à base da orelha e estende-se ventralmente ao olho esquerdo. A lesão observada na região central do crânio corresponde à perfuração pelo dardo cativo usado no abate em matadouro-frigorífico.

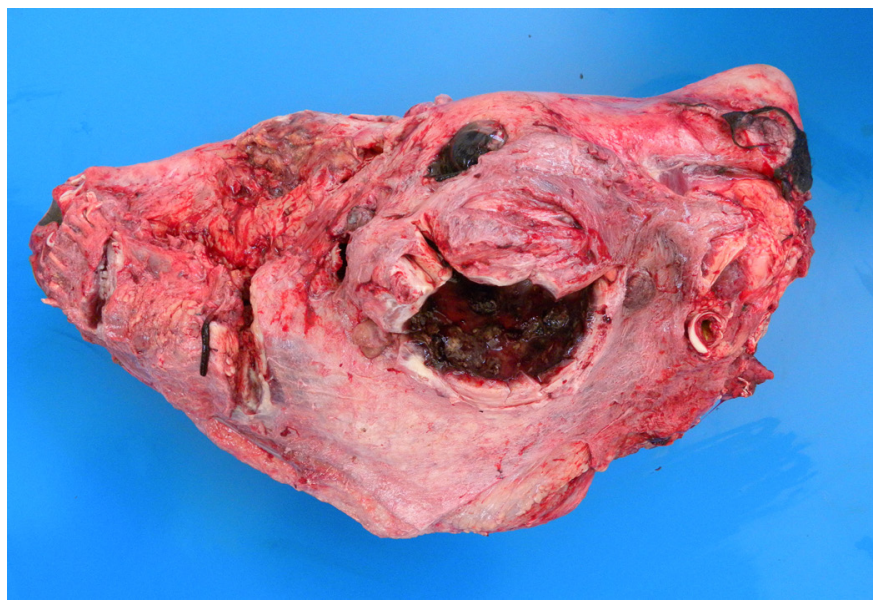

Fig.2. Actinomicose em bovino (Caso 2). Na região do masseter pode-se ver uma cavidade preenchida por material preto (necrose), friável e fétido. 


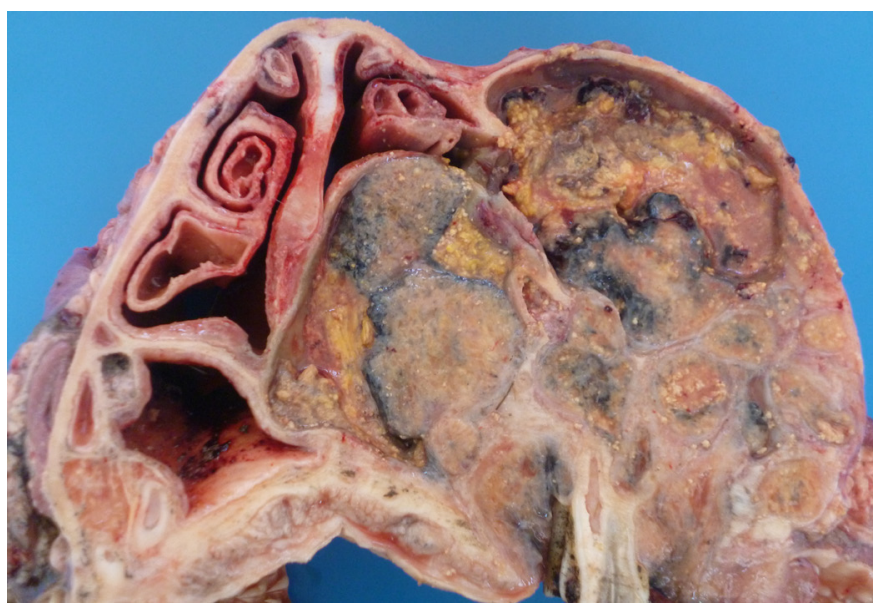

Fig.3. Actinomicose em bovino (Caso 1). Na maxila direita há extensa massa óssea com múltiplos nódulos amarelos com aspecto caseoso, circundados por finos septos de tecido ósseo (osteomielite piogranulomatosa). A reação inflamatória causou destruição de parte dos cornetos nasais e obstrução quase que total da cavidade com desvio do septo nasal contralateral.

Microscopicamente, as lesões eram caracterizadas por múltiplos piogranulomas em meio a trabéculas ósseas bem definidas (Fig.4). No centro desses piogranulomas podiam-se observar estruturas constituídas por uma massa interna de bacilos filamentosos gram-positivos (corados em azul pela técnica de Gram) e uma periferia com clavas eosinofílicas radiais (reação de Splendore-Hoeppli), circundadas por neutrófilos, macrófagos e ocasionais células gigantes multinucleadas. Mineralização das reações de Splendore-Hoeppli foi observada ocasionalmente nos casos aqui descritos. Extensa reação fibrosa com infiltração por neutrófilos, linfócitos e plasmócitos circundava os piogranulomas e se estendia aos tecidos moles adjacentes. Em algumas seções coradas pela HE foram observados bacilos fracamente ba-

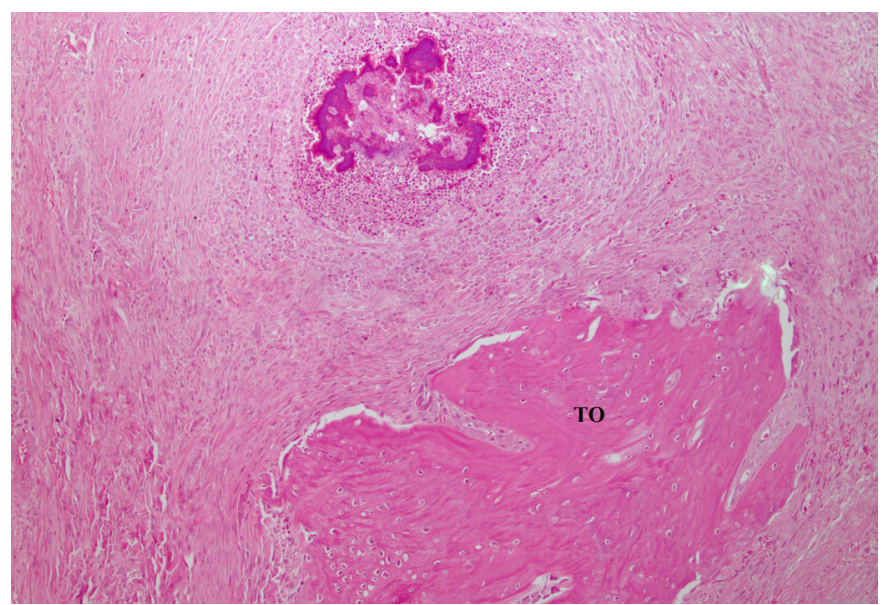

Fig.4. Actinomicose em bovino (Caso 1). Osteomielite piogranulomatosa. Piogranuloma em meio a trabéculas ósseas (T0). No centro desses piogranulomas (porção central superior da figura) podem ser observadas estruturas constituídas por uma massa interna de bacilos filamentosos que, na coloração de Gram, coravam-se de azul, e uma periferia com clavas eosinofílicas radiais (reação de Splendore-Hoeppli), circundadas por neutrófilos e macrófagos epitelioides. HE, obj.20x.

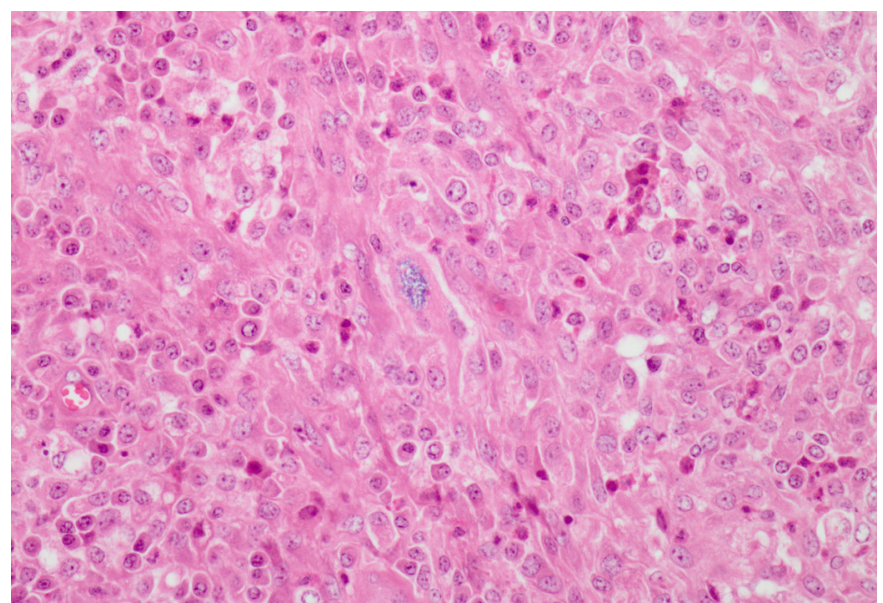

Fig.5. Actinomicose em bovino (Caso 1). Observam-se bacilos fracamente basofílicos no interior de grande macrófago epitelioide. HE, obj.40x.

sofílicos no interior de macrófagos epitelioides (Fig.5) células gigantes multinucleadas e em meio às clavas eosinofílicas. Fragmentos dessas clavas também foram fagocitados por células gigantes multinucleadas.

\section{DISCUSSÃO}

A maioria dos autores afirma que o envolvimento da mandíbula nos casos de actinomicose é muito mais frequente, sendo rara a localização em outros ossos (Wilson 2005, Thompson 2007, Serakides 2011). Provavelmente esse maior acometimento da mandíbula ocorra porque as partículas vegetais tendem a serem forçadas para baixo pela mastigação, introduzindo-se entre o dente e a gengiva, proporcionando uma porta de entrada para a bactéria (Boström 1890). Além disso, a própria troca dentária em bovinos, restrita à arcada inferior, favorece esse maior acometimento do osso mandibular (Radostits 2007). Em nenhum dos casos descritos aqui foram observadas lesões na cavidade oral; provavelmente, pelo tempo de evolução prolongado da lesão, feridas na mucosa oral superior, que poderiam ter servido de portas de entrada para a infecção, já estavam curadas no momento do abate.

Lesões de actinomicose podem aumentar rapidamente de tamanho em poucas semanas, porém normalmente crescem lentamente ao longo de meses (Radostits 2007). 0 envolvimento ósseo e muscular torna-se tão acentuado que a dificuldade de apreensão e mastigação com consequente perda progressiva de peso são comumente observadas nos bovinos afetados (Seifi et al. 2003, Serakides 2011). Nos casos onde há envolvimento acentuado da maxila pode ocorrer dificuldade respiratória (Radostits 2007). Apesar de não haver informações sobre os sinais clínicos dos bovinos deste relato, a gravidade das lesões faz supor que apresentassem dispneia em decorrência da obstrução parcial da cavidade nasal.

$\mathrm{Na}$ osteomielite por actinomicose, inicialmente se formam tratos supurativos nos espaços medulares levando a múltiplos focos de reabsorção e proliferação óssea. Sequestro ósseo não ocorre, mesmo quando o córtex é invadido, provavelmente devido à natureza lenta e progressiva da doença 
(Thompson 2007). As fístulas observadas nos tecidos moles desses casos são achados comuns na actinomicose, frequentemente ocorrendo comunicação desses trajetos fistulosos com a boca ou com a pele da região afetada (Wilson 2005).

Os pequenos grânulos amarelos duros observados no centro dos nódulos caseosos em ambos os casos são denominados coloquialmente de grânulos de enxofre devido à cor (Brewer 1956); representam as colônias bacterianas e não são específicos para a actinomicose (Miller \& Haddad 1998). Microscopicamente, essas estruturas correspondem à reação de Splendore-Hoeppli. Agregados de filamentos gram-positivos aparecem associados à reação de Splendore-Hoeppli e a fragmentação desses filamentos produz as formas coco-bacilares, mais observadas nas áreas centrais dos grânulos, enquanto a natureza filamentosa da bactéria é mais aparente na periferia (Ginn et al. 2007).

Pouco se sabe sobre como os fatores de virulência, as interações ligante-receptor, as células-alvo, as toxinas, as moléculas anti-fagocíticas da cápsula bacteriana e outros fatores participam da patogenicidade de Actinomyces bovis. Porém, assim como Actinobacillus lignieresii, provavelmente, $A$. bovis também seja capaz de escapar à destruição por neutrófilos e macrófagos, colonizando os próprios abscessos nos tecidos. Essa resistência do agente à fagocitose leva à formação de agregados proteináceos eosinofílicos de imunoglobulinas em sua superfície, que podem ser visualizados histologicamente como a reação de Splendore-Hoeppli (Zachary 2012). Os bacilos fracamente basofílicos observados em algumas seções de HE no interior de macrófagos epitelioides e células gigantes multinucleadas são morfologicamente semelhantes aos bacilos corados pela técnica de Gram em outras seções e sugerem que essas bactérias tenham sido fagocitadas.

Reações teciduais semelhantes ocorrem com outras bactérias, particularmente Actinobacillus lignieresii, porém as colônias na actinomicose são maiores e as clavas são menores e menos discretas do que na actinobacilose e, geralmente, localizadas na periferia das colônias (Till \& Palmer 1960). Além disso, actinobacilose é uma doença de tecidos moles e os coco-bacilos, diferentemente dos da actinomicose, são gram-negativos (Grist 2008). Essa distribuição das clavas eosinofílicas perifericamente pode ser observada na maioria das reações de Splendore-Hoeppli desses bovinos, porém, isoladamente, não parece ser uma característica morfológica confiável para estabelecer o diagnóstico. Fusobacterium necrophorum e outras bactérias não específicas podem causar osteomielite por extensão direta de periodontite, no entanto, as lesões são usualmente mais destrutivas e menos proliferativas (Thompson 2007).
Nos casos aqui descritos, devido à grande extensão e características invasivas das lesões, uma condição necessariamente incluída no diagnóstico diferencial macroscópico é o carcinoma de células escamosas intranasal, um dos neoplasmas da cavidade nasal mais comumente observado em ruminantes. A superfície de corte desses tumores pode apresentar pequenas estruturas amarelas, que representam as pérolas de ceratina (Wilson \& Dungworth 2002), as quais em um exame macroscópico menos detalhado poderiam facilmente ser confundidas com os grânulos de enxofre da actinomicose.

\section{REFERÊNCIAS}

Basile J.R. \& Diniz J.M.F. 1979. Actinomicose no pênis de bovino. Semina 1:45-46.

Bertonce A.L. \& Rebhun W.C. 1984. Tracheal actinomycosis in a cow. J. Am. Vet. Med. Assoc. 185:221-222.

Boström 1890. Untersuchungen über die Aktinomykose des Menschen. Beitr. Path. Anat. Allg. Pathol. 9:1-240.

Brewer J.S. 1956. Discussion and case history: actinomycosis. Iowa Ste. Univ. Vet.. 18:145-208.

Ginn P.E., Mansell J.E.K.L. \& Rakich P.M. 2007. Skin and appendages, p.553781. In: Maxie M.D. (Ed.) Jubb, Kennedy \& Palmer Pathology of Domestic Animals. Vol.1. $5^{\text {th }}$ ed. Elsevier Saunders, Philadelphia.

Grist A. 2008. Conditions encountered at bovine post mortem inspection (non Parasitic), p.160-239. In: Ibid. (Eds), Bovine Meat Inspection. $2^{\text {nd }}$ ed. Nottingham University Press, Nottingham.

McFadyean S.J. 1932. Actinomycosis \& Actinobacillosis. J. Comp. Pathol Therap. 45:93-105.

Jones T.C., Hunt R.D. \& King N.W. 1997. Actinomycosis, p.482-484. In: Ibid. (Eds), Veterinary Pathology. $6^{\text {th }}$ ed. Williams and Wilkin, Baltimore.

Miller M. \& Haddad A.J. 1998. Cervicofacial actinomycosis. Oral Surg. Oral Med. Oral Pathol. 85:496-508.

Radostits O.M., Gay C.C., Hinchcliff K.W. \& Constable P.D. 2007. Diseases associated with bacteria, p.1007-1060. In: Ibid. (Eds), Veterinary Medicine: a textbook of the diseases of cattle, horses, sheep, pigs, and goats. $10^{\text {th }}$ ed. Saunders Elsevier, Spain.

Serakides R. 2011. Ossos e articulações, p.647-696. In: Santos R.L. \& Alessi A.C. (Eds), Patologia Veterinária. Roca, São Paulo.

Till D.H. \& Palmer F.P.A. 1960. A review of actinobacillosis with a study of the causal organism. Vet. Rec. 72:527-543.

Thompson K. 2007. Inflammatory diseases of bones, p.92-105. In: Maxie M.D. (Ed.), Jubb, Kennedy \& Palmer Pathology of Domestic Animals. Vol.1. $5^{\text {th }}$ ed. Elsevier Saunders, Philadelphia.

Zachary J.F. 2012. Mechanisms of microbial infections, p.147-241. In: Zachary J.F. \& McGavin M.D. (Eds), Pathologic Basis of Veterinary Disease. $5^{\text {th }}$ ed. Elsevier, St. Louis.

Wilson D.W. \& Dungworth D.L. 2002. Tumors of the Respiratory Tract, p.365-399. In: Meuten D.J. (Ed.), Tumors in Domestic Animal. Iowa State Press, Ames.

Wilson W.G. 2005. Specific Diseases, p.112-136. In: Ibid. (Ed.), Wilson's Practical Meat Inspection. 7 th ed. Blackwell, Oxford. 